\title{
INFLUENCE OF GROUTING PRESSURE VOLATILITY ON ADDITIONAL RESPONSE OF ADJACENT PILE FOUNDATION IN SHIELD CONSTRUCTION ${ }^{1}$
}

\author{
Chuan-Chuan Zhang, Dan-Mei Li, Jun Zhang \\ Shanxi Transportation Technology Research and Development Co., Ltd., Taiyuan, Shanxi Province, China \\ Key Laboratory of Highway Construction and Maintenance Technique in Loess Area, Taiyuan, Shanxi Province, China \\ e-mail: zccmech2012@163.com (Chuan-Chuan Zhang)
}

TONG-SHEng YU

Central Southern China Electric Power Design Institute Co. LTD of China Power Engineering Consulting Group, Wuhan, China

\section{QIANG CHEN}

China Railway Siyuan Group Southwest Survey and Design Co. Ltd, Kunming, China

\begin{abstract}
Soil parameters along the heading direction are subjected to spatial variability during shield construction, so grouting pressure requires constant adjustment to ensure ground stress stability. This causes grouting pressure to fluctuate around the design pressure/curve. Therefore, the influence of the grouting pressure volatility on the adjacent loaded-pile foundation should be considered in shield tunneling. In this study, a refined numerical simulation of the shield construction process is conducted using the Fast Lagrangian Analysis of Continua in Three Dimensions (FLAC3D) software. A total of 300 groups of grouting pressure parameters with a skewed normal distribution are input into the numerical model. Then, the influence of the construction parameter uncertainty on the adjacent loaded-pile foundation is analyzed. Finally, the back analysis method is conducted based on the monitored data to evaluate how the construction process affects the pile foundation. The calculation results are compared with those of the traditional finite element method. The results indicate that in the tunneling process, the grouting pressure fluctuation greatly affects the additional bending moment of the adjacent pile foundation. Under the influence of the grouting pressure, the additional axial force and additional bending moment of the pile foundation also follow the skewed normal distribution. The back analysis results of the pile foundation are greater than those of the typical numerical method by about $60 \% 100 \%$, that is using the back analysis calculation results to evaluate the pile foundation additional response can reduce the risk.
\end{abstract}

Keywords: grouting pressure fluctuations, adjacent loaded-pile foundation, normal distribution, FLAC3D

\section{Introduction}

In the recent years, an increase in urbanization has resulted in rapid development of urban underground rail transit and space development projects. Many countries begin to build subways to address the increasing demand for adaptation. Shield tunneling has many advantages, such as high efficiency of mechanized construction and a small effect on the underground pipeline, pile foundation, ground deformation and ground traffic. Therefore, this method is often considered

\footnotetext{
${ }^{1}$ Paper presented at the 4th International Conference on Material Strength and Applied Mechanics, MSAM 2021
} 
the best choice for subway tunnel construction (Liu et al., 2020; Lv et al., 2020; Yang et al., 2020; Cui et al., 2020).

The adjacent loaded-pile foundation has been used in shield construction, making the measuring points difficult to arrange on the pile. The influence of the shield tunnel construction process on the adjacent loaded-pile foundation is also hard to evaluate. Such engineering or research problems are commonly analyzed using three methods: model test, two-stage analysis and numerical simulation. The first method requires considerable manpower, material, financial resources and time (Bezuijen and Schrier, 2005; Loganathan et al., 2000). However, given the effect size, some test results cannot be directly used to guide the engineering practice (Lee and Bassett, 2007; Lee and Yoo, 2006). In the second method (Wang et al., 2014; Zhang, 2011), the soil is usually assumed as a uniform elastic medium. The coupling effect between the excavation of the soil and the response of the pile foundation is also not considered, which is quite different from the engineering practice. The third method selects the most suitable constitutive model to reflect the elastoplastic soil characteristics. Thus, it has been widely used in simulating various complex construction processes, including different working conditions and subway structures (Chen et al., 2018; Li et al., 2020; Zhang et al., 2020).

Chen et al. (2018) simulated slurry fracturing during shield tunneling using a numerical method and reproduced the fracture initiation, branching and propagation. Similarly, Li et al. (2020) used a numerical method to simulate and analyzed the pile underpinning technology during shield tunnel crossing bridge pile foundation construction. Zhang et al. (2020) emulated a curved shield tunnel under yaw excavation loadings by utilizing a numerical simulation method. They found that under dual action of overcutting and construction loadings, the surface settlement of a curved tunnel was larger than that of a straight-line tunnel. The current study employed a numerical calculation method to simulate the construction process of a metro tunnel. A refined numerical simulation of the shield construction process was conducted using the Fast Lagrangian Analysis of Continua in Three Dimensions (FLAC3D) software (FLAC3D 3.0, 2009). In this paper, numerical simulation was used to simulate the shield tunnel construction process and evaluate its influence on the adjacent loaded-pile foundation.

In shield construction, soil material parameters are subjected to spatial variation (Fenton and Griffiths, 2002; Griffiths and Fenton, 2004; Griffiths et al., 2009; Zhang et al., 2018), and construction parameters (e.g., grouting pressure) require continuous adjustment with a change of geological parameters (Aydan and Hasanpour, 2019). Soil parameter spatial variability has been considered in studying the slope slip (Griffiths et al., 2009), stability of embankment (Zhang et al., 2018), liquefaction of foundation (Baker and Faber, 2008), and stability evaluation of a tunnel-boring machine-driven tunnel face (Eshraghi and Zare, 2014). Prior findings showed that ignoring the spatial parameter variability underestimated the danger of the damage. The spatial variability of soil parameters and other factors make the grouting pressures fluctuate around the design pressure/curve during construction. This issue should be highly concerned when evaluating the effect of shield tunneling on adjacent loaded-pile foundations. Otherwise, calculation results will be inaccurate. Zheng et al. (2015) showed that among many construction parameters, the grouting pressure is highly uncertain. They also found that it had the most significant influence on formation of deformation. So, the influence of the grouting pressure on the adjacent loaded-pile foundation is studied.

Using the numerical simulation method of previous studies and considering the most important influencing factors in the existing literature, a method to evaluate the influence of shield construction on the adjacent loaded-pile foundation was established. The current paper proceeds as follows. A numerical model of the shield tunneling of the Taiyuan Metro Line 2 passes through the pile foundation group of Xuefu Street Highway Bridge is established in Section 2, and the influence of the grouting pressure fluctuation on the adjacent loaded-pile foundation is researched in Section 3. A total of 300 groups of grouting pressure data with the skewed 
normal distribution are used as input parameters to simulate the shield tunneling process. Their effect on the pile foundation group of the highway bridge is evaluated. The numerical method can be used to predict the influence range of the grouting pressure fluctuation on pile foundation. However, the calculation amount is too large. In order to evaluate the influence on the pile foundation using the monitored surface settlement data along Line 2, the following two steps are performed in Section 4. First, a mapping model between grouting pressure follows the skewed normal distribution and surface settlement is established through artificial intelligence learning methods. Then, the grouting pressures are derived from the monitored data and input into the proposed numerical model simulating the shield tunneling. Although this study has limitations, the simulation results can still provide an idea and basis for further investigations on the influence of construction parameter uncertainty on the adjacent load-pile foundation.

\section{Numerical simulation model and method}

\subsection{Description of the numerical simulation model}

The proposed numerical simulation model was derived from a section of Taiyuan Metro Line 2 between Xuefu Street Station and Changfeng Street Station. This section has length of $105.6 \mathrm{~m}$ and two lines of the shield tunnel. The shield segment has an outer diameter of $6.2 \mathrm{~m}$, thickness of $0.35 \mathrm{~m}$, and width of $1.2 \mathrm{~m}$. The buried depth of the tunnels is $10.5 \mathrm{~m}-12.9 \mathrm{~m}$. From Xuefu Street to Changfeng Street, a downward slope of $2 \%$ is also designed. In this study, the analysis is focused on the influence on loaded-pile foundations when the shield construction crosses the Xuefu Street Highway Bridge. A pile foundation group of the highway bridge contains $3 \times 3$ bored piles with diameter of $1.5 \mathrm{~m}$ and length of $60 \mathrm{~m}$. The closest distance between the left tunnel and the left pile foundation is $12.5 \mathrm{~m}$, and the closest distance from the right tunnel to the right pile foundation is $13.8 \mathrm{~m}$, as shown in Fig. 1. The field situation is presented in Fig. 2 .

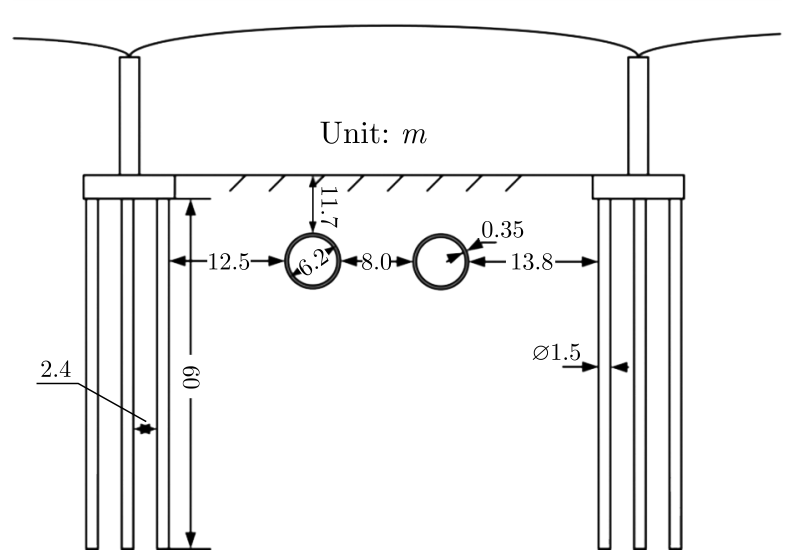

Fig. 1. Relative positions of the shield tunnel and pile foundation of the viaduct

On the basis of the above design drawings, a 3D calculation model was established with length of $100 \mathrm{~m}$, width of $105.6 \mathrm{~m}$ (in depth), and height of $65.3 \mathrm{~m}$, as shown in Fig. 3. The distance between the left tunnel construction and the left pile foundation is relatively close. The distance from the right pile foundation to the left tunnel construction is three times larger than the tunnel diameter. The influence of the left tunnel construction on the right pile foundation might be neglected. Therefore, a simulation was carried out only for the left tunnel construction, and analysis was conducted to determine the influence on the additional response of the left pile foundation. 


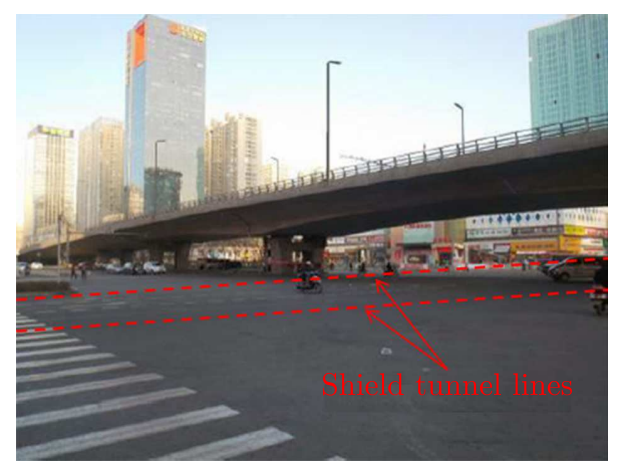

Fig. 2. Field situation of relative positions

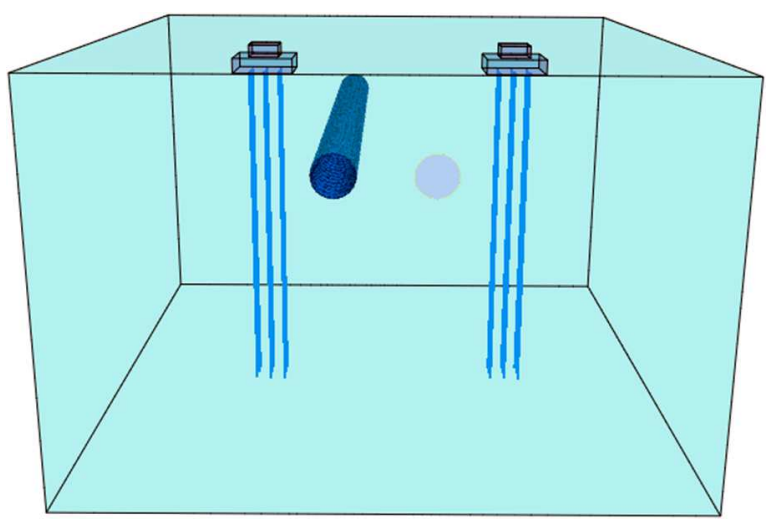

Fig. 3. 3D geometric model

\subsection{Description and characterization of grouting pressure parameter fluctuation}

In shield tunneling, geological parameters along the forward direction of the shield machine are generally spatially variable. Combined with the influence of human operation factors, the grouting pressure requires constant adjustment to ensure the ground stress balance and prevent abrupt changes of ground subsidence or excessive deformation of surrounding structures. This method will make the grouting pressure fluctuate within a specific range around the design pressure value/curve. The grouting pressure data analysis and distribution fitting test results of engineering examples in the literature showed that a skewed normal distribution could describe the uncertainty distribution law of the grouting pressure. Moreover, its correlation distance is more reasonable to take four rings (Wang and $\mathrm{Yu}, 2019$ ). In the current study, a total of 300 groups of data were randomly generated to represent the grouting pressure fluctuation. In each group, the number of grouting pressure data is equal to the number of shield rings, and they obeyed the skewed normal distribution. And they would be input into the model in turn in the next stage of shield construction simulation. The average value of each group of data was $0.18 \mathrm{MPa}$ for the design grouting pressure. The coefficient of variation was the maximum value of the analysis results, i.e., $\operatorname{Cov}=0.25$. Finally, its reliability was verified (for more details, refer to Wang and $\mathrm{Yu}, 2019)$.

\subsection{Numerical simulation process}

After discretization of the above geometric models, a Fast Lagrangian Finite Difference model was obtained. In the model, eight-node hexahedral solid elements were used for the discretization of the soil mass. Then, a Mohr-Coulomb constitutive relation was used for simulation. The tunnel shield machine shell was discrete by the solid element, and a linear elastic constitutive relation 
was adopted given its relatively large stiffness. The tunnel segment was simulated using the line elastic shell element. The reinforced concrete viaduct cap was modeled 1:1 and dispersed to the solid element, and the viaduct above the cap and other loads were replaced with an equivalent load. The pile element in the structural element was used to simulate the bridge pile foundation group. The soil parameters adopted are shown in Table 1. The other material parameters were taken as the standard values in relevant design specifications.

Table 1. Soil parameters

\begin{tabular}{|c|c|c|c|c|c|c|}
\hline $\begin{array}{c}\text { Soil } \\
\text { layer } \\
\text { number }\end{array}$ & $\begin{array}{c}\text { Depth } \\
h[\mathrm{~m}]\end{array}$ & $\begin{array}{c}\text { Cohesive } \\
\text { force } \\
c[\mathrm{kPa}]\end{array}$ & $\begin{array}{c}\text { Frictional } \\
\text { angle } \\
\varphi\left[^{\circ}\right]\end{array}$ & $\begin{array}{c}\text { Modulus of } \\
\text { compression } \\
E[\mathrm{MPa}]\end{array}$ & $\begin{array}{c}\text { Natural } \\
\text { gravity } \\
\rho\left[\mathrm{kN} / \mathrm{m}^{3}\right]\end{array}$ & $\begin{array}{c}\text { Poisson's } \\
\text { ratio } \\
\nu[-]\end{array}$ \\
\hline 1-1 Miscellaneous fill & 0 to -1.2 & 4 & 5 & 8 & 19.0 & 0.45 \\
\hline 1-2 Plian fill & -1.2 to -3.2 & 4.7 & 6 & 10 & 19.0 & 0.43 \\
\hline 2-3-1 Clayey silt & -3.2 to -4.5 & 7.7 & 18.5 & 13 & 19.8 & 0.4 \\
\hline 2-2 Silty clay & -4.5 to -11 & 9.7 & 11.2 & 10 & 19.8 & 0.4 \\
\hline 2-4 Silty-fine sand & -11 to -13.1 & 3.2 & 25 & 19 & 20.5 & 0.32 \\
\hline 2-3-1 Clayey silt & -13.1 to -17.5 & 7.7 & 18.5 & 13 & 19.8 & 0.4 \\
\hline 2-5 Medium sand & -17.5 to -32.9 & 2.1 & 28 & 30 & 20.2 & 0.32 \\
\hline 3-3 Silty clay & -32.9 to -38.5 & 18.6 & 13.7 & 16 & 19.6 & 0.38 \\
\hline 3-11 Cobbly soil & -38.5 to -45.3 & 13.2 & 20.3 & 14 & 20.6 & 0.4 \\
\hline 3-4-1 Clayey silt & -45.3 to -65.3 & 20 & 18 & 32 & 19.6 & 0.38 \\
\hline
\end{tabular}

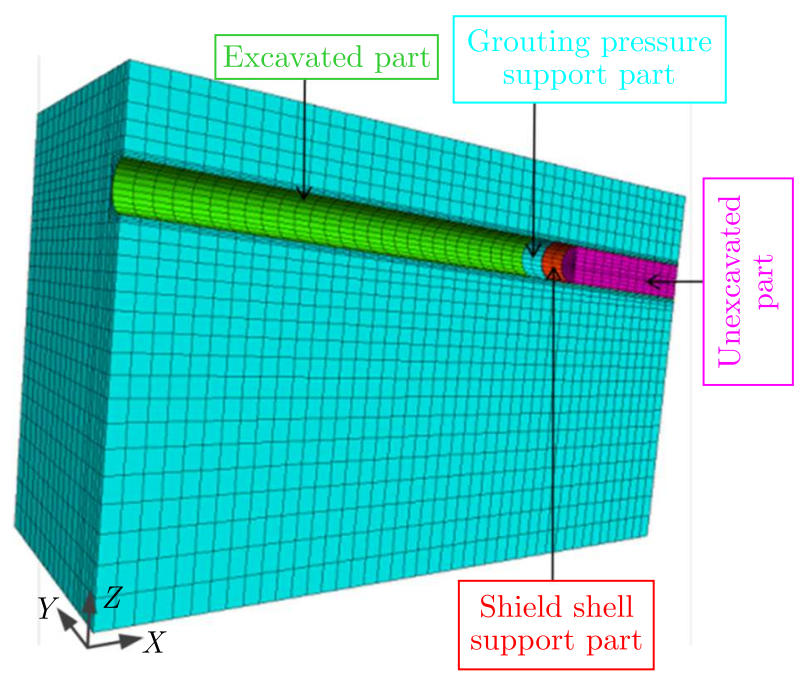

Fig. 4. Schematic of the shield tunneling process

The simulation process was mainly divided into two stages. The first stage was obtaining the in-situ stress. Specifically, the initial in-situ stress field was the state without viaduct pile foundation. After pile foundations were added, the displacement velocity field was calculated until the equilibrium state. Then, the displacement velocity field was cleared as a new initial stress field. The second stage was a simulation of the shield tunneling process. This stage involved four steps: shield machine tunneling, shield shell support, grouting pressure support and segment pipe support. These steps were repeated to simulate the entire shield construction process. In shield machine tunneling, soil elements in the tunneling range were assigned to the empty model, and a jacking force was applied to the tunnel face. In the shield shell support, segment elements were changed into elastic elements, and the shield shell parameters were assigned. In the grouting pressure support, shield shell elements at the shield machine tail were assigned as 
an empty model, and the grouting pressure was applied to the soil around the tunnel. In this step, 300 grouting pressure parameters generated earlier were input to the numerical simulation model. In the segment pipe support, the grouping pressure parameters were removed, and the shell element parameters at the relative position were changed to the segment pipe parameters. The schematic of the shield tunneling process is shown in Fig. 4. In theory, a simulation model containing 88 rings should repeat the second stage discussed above 88 times. However, in the current study, the simulated construction step excavated two rings considering the time cost of calculation (for 300 groups of grouting pressure data to calculate 300 models). In other words, the shield tunneling process of the left tunnel was simulated 44 times in the whole section. Finally, the influence of shield tunneling processes on the adjacent loaded-pile foundation additional response was analyzed.

\section{Simulation results and analysis}

\subsection{Simulation results}

One of the calculation results of 300 groups of the grouting pressure was extracted and analyzed. The total displacement cloud map of pile foundations in the vertical direction is shown in Fig. 5a. The deformation law of nine pile foundations was roughly the same. The upper part of the pile foundation had the largest downward displacement, and the bottom had a small upward deformation due to excavation unloading. Therefore, in the subsequent analysis, the pile close to the shield tunnel and the starting position can be selected as a representative to analyze the influence on additional deformation of the pile foundation.

(a)

Pile X-Displacement
$4.3527 \mathrm{E}-03$
$4.2500 \mathrm{E}-03$
$4.0000 \mathrm{E}-03$
$3.7500 \mathrm{E}-03$
$3.5000 \mathrm{E}-03$
$3.2500 \mathrm{E}-03$
$3.0000 \mathrm{E}-03$
$2.7500 \mathrm{E}-03$
$2.5000 \mathrm{E}-03$
$2.2500 \mathrm{E}-03$
$2.0000 \mathrm{E}-03$
$1.7500 \mathrm{E}-03$
$1.5000 \mathrm{E}-03$
$1.2500 \mathrm{E}-03$
$1.0000 \mathrm{E}-03$
$7.5000 \mathrm{E}-04$
$5.0000 \mathrm{E}-04$
$2.5000 \mathrm{E}-04$
$0.0000 \mathrm{E}+00$
$-2.3704 \mathrm{E}-04$

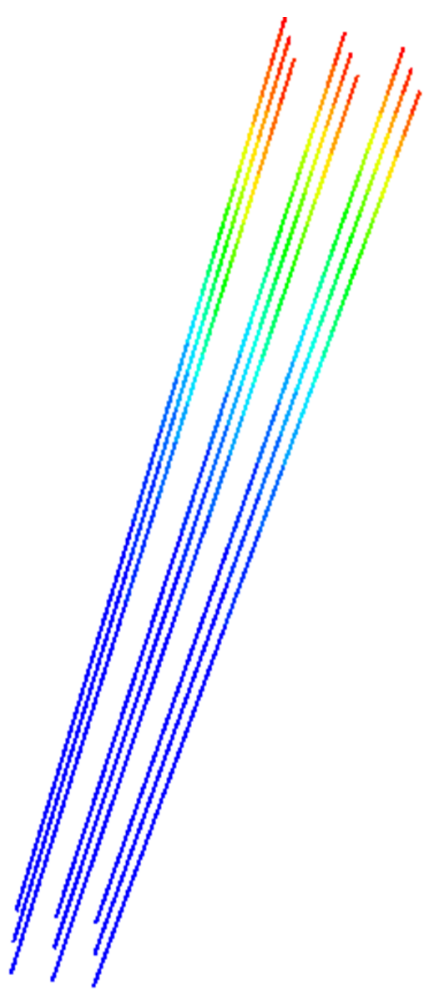

(b)

Pile x-component force

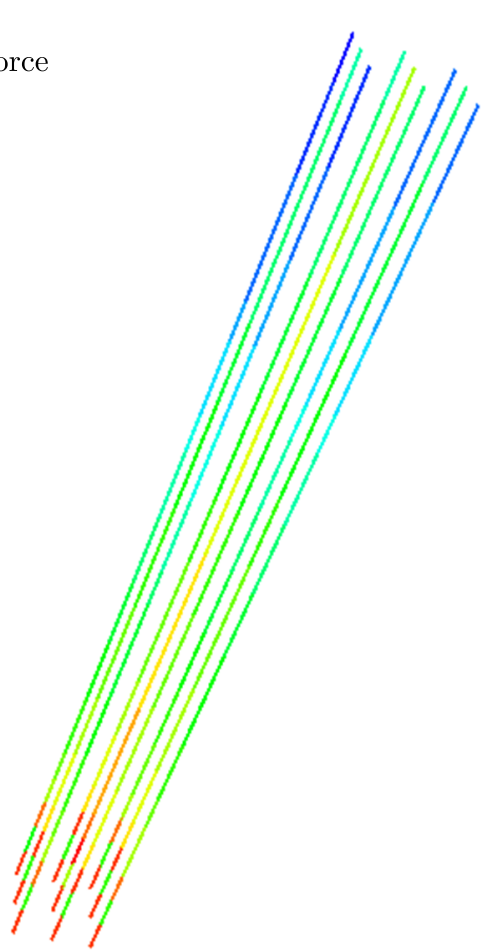

Fig. 5. (a) Total vertical displacement cloud and (b) total axial force diagram of pile foundations

The total axial force diagram of piles is shown in Fig. 5b. The change gradient of the axial force of four pile foundations at the four corners was larger than that of the rest of the five piles, and the pile axial force had almost no difference between the four piles at the four corners. 
Therefore, in the subsequent analysis, the pile near the shield tunnel and the starting position can also be selected as a representative to analyze its effect on the additional axial force of pile foundations.

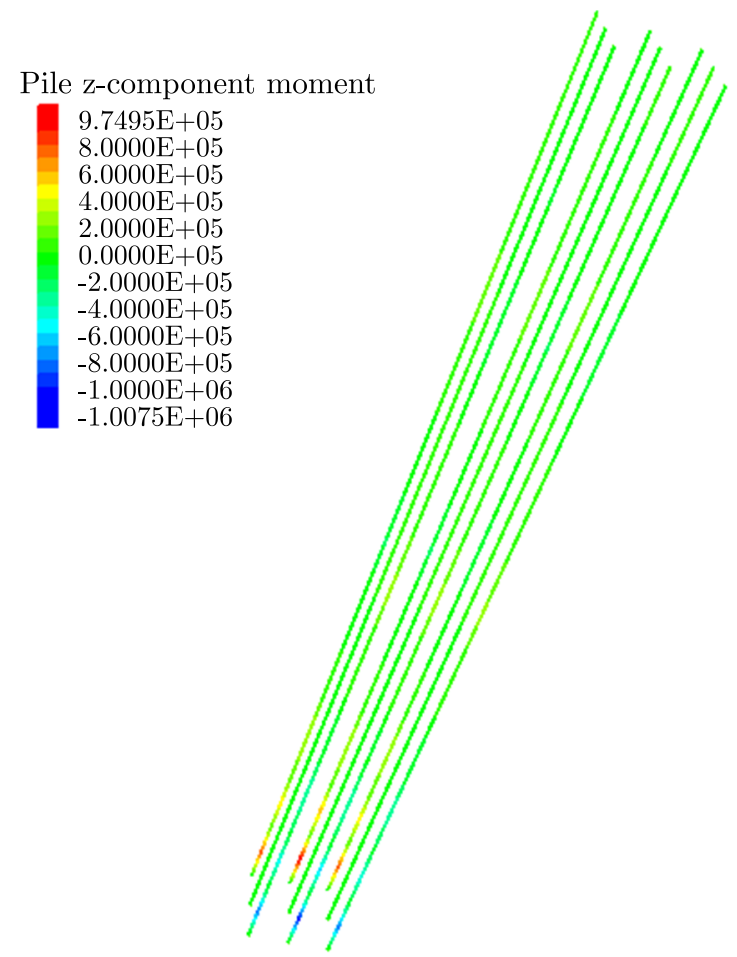

Fig. 6. Total bending moment diagram of the pile foundation

The total bending moment diagram of pile foundations is shown in Fig. 6. The change gradient of the bending moment of piles in front and rear rows was large. The bending moment at the bottom of these two rows of pile foundations was positive and negative, respectively. The bending moment gradient of the row near the starting station was slightly larger. Therefore, in the subsequent analysis, the pile foundation near the shield tunnel and the starting position can also be selected as a representative to analyze its effect on the additional bending moment of the pile foundation.

\subsection{Analysis of the influence of grouting pressure parameter fluctuation}

On the basis of the above analysis, the deformation, axial force and bending moment of the pile were extracted for 300 groups of grouting pressure parameters, and the influence law of grouting pressure fluctuation on the additional response of the adjacent pile foundation under load was analyzed.

The total lateral movement results of the pile foundation for 300 groups of grouting pressures are shown in Fig. 7a. The lateral movement of the pile foundation was extremely different considering the grouting pressure fluctuation. In the most unfavorable case, the lateral movement at the top of the pile is approximately $5 \mathrm{~mm}$. However, the minimum lateral movement of the pile foundation is $0.3 \mathrm{~mm}$ among the 300 groups of calculation results. The total lateral displacement standard deviation of the pile foundation considering the uncertainty of grouting pressure, with the maximum value of approximately $0.8 \mathrm{~mm}$, is depicted in Fig. $7 \mathrm{~b}$. A reasonable grouting pressure could effectively control the additional deformation of the pile. Otherwise, it had adverse effects on the pile deformation and might bring great hidden danger to safety. 

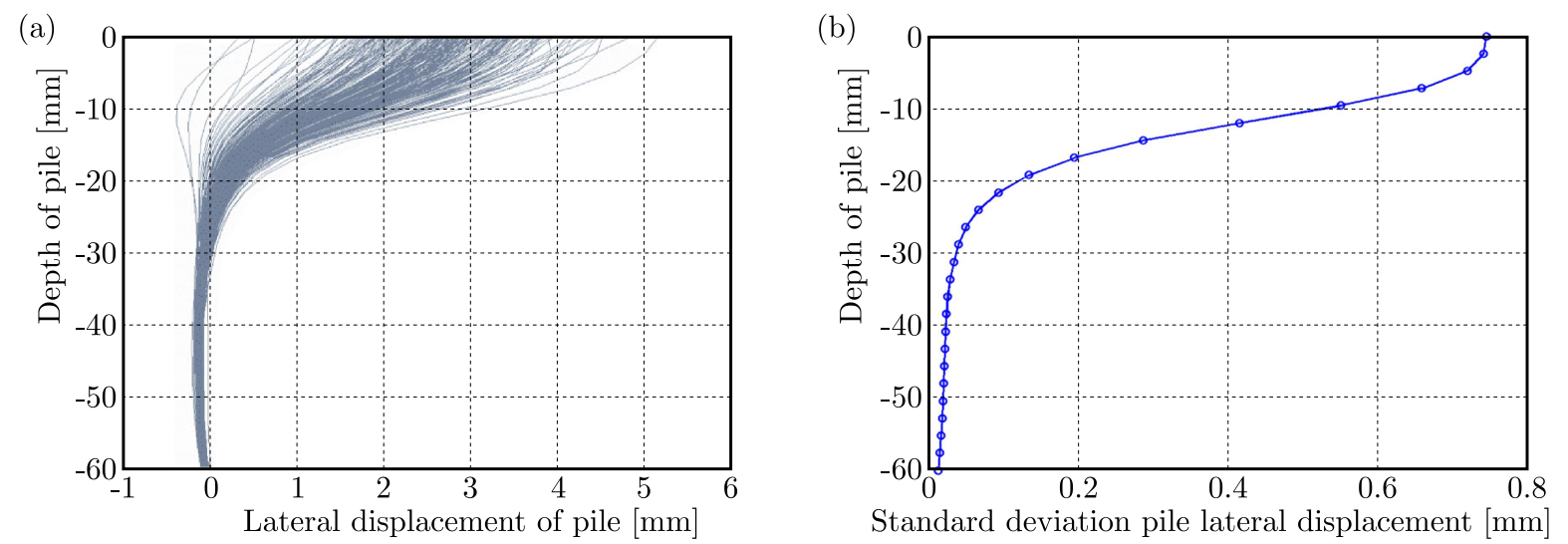

Fig. 7. (a) Total pile foundation lateral displacement under grouting pressure of 300 groups. (b) The standard deviation of the total pile foundation lateral displacement
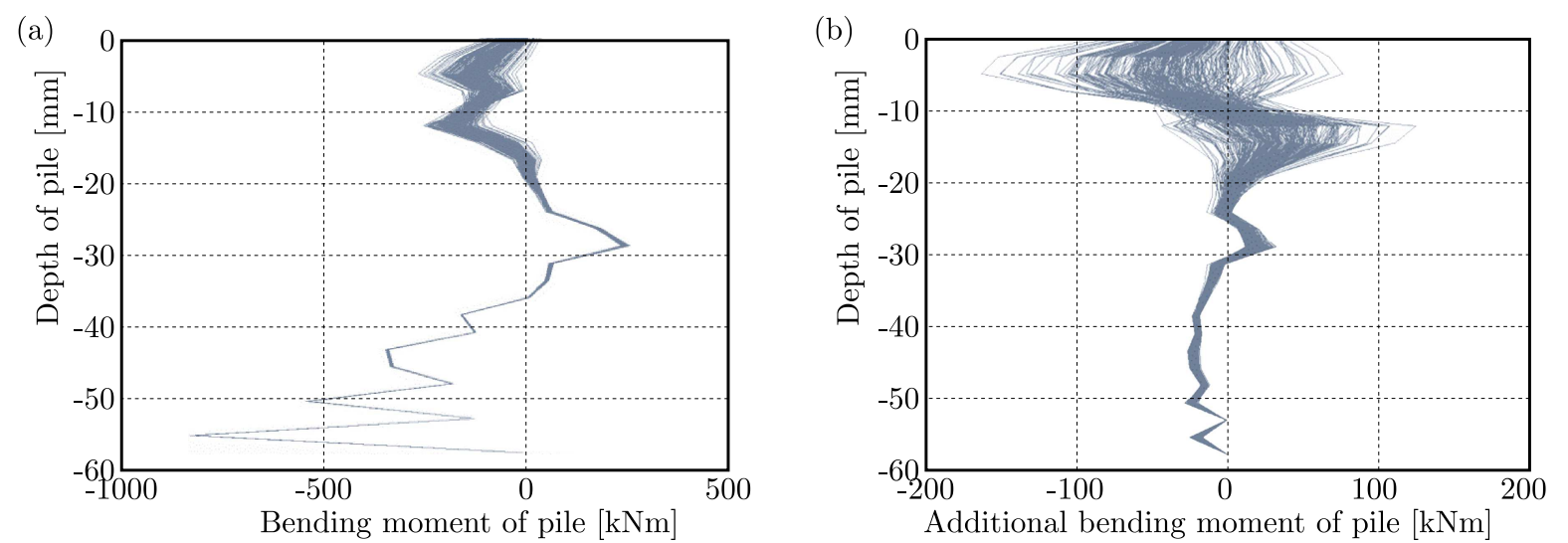

Fig. 8. (a) Total and (b) additional bending moments of pile foundation

The calculation results of the total pile foundation bending moment and under grouting pressure of 300 groups are shown in Fig. 8a. The additional bending moment during shield construction under grouting pressure of 300 groups are shown in Fig. 8b. The influence on the additional bending moment of the pile mainly occurred in depth of approximately $30 \mathrm{~m}$ below the surface, considering the grouting pressure uncertainty. Within this range, the maximum total bending moment of the pile body was approximately $250 \mathrm{kN} \cdot \mathrm{m}$, and the maximum additional bending moment was approximately $100 \mathrm{kN} \cdot \mathrm{m}$. In other words, around $40 \%$ of the pile bending moment was caused by the shield tunnel construction. In some sections, the proportion of the pile additional bending moment value to the bending moment was extremely high. Thus, the grouting pressure uncertainty had a great influence on the response of the pile additional bending moment. The additional response brought by the construction parameter fluctuation to the pile foundation should be fully considered in the design and the strengthening process. Otherwise, it might lead to safety accidents. The standard deviation of the additional bending moment of the pile foundation considering the grouting pressure uncertainty is shown in Fig. 9a. The influence of the grouting pressure fluctuation on the additional bending moment decreased significantly when the buried depth of the pile foundation was greater than $30 \mathrm{~m}$ (approximately 2.5 times deeper than the tunnel buried depth).

The calculation results of the total axial force of the pile foundation under 300 groups of grouting pressures are shown in Fig. 9b, and the additional axial force of the pile foundation during shield construction under 300 groups of grouting pressures are shown in Fig. 10a. The additional axial force of the pile had fluctuation characteristics, considering the grouting pressure 

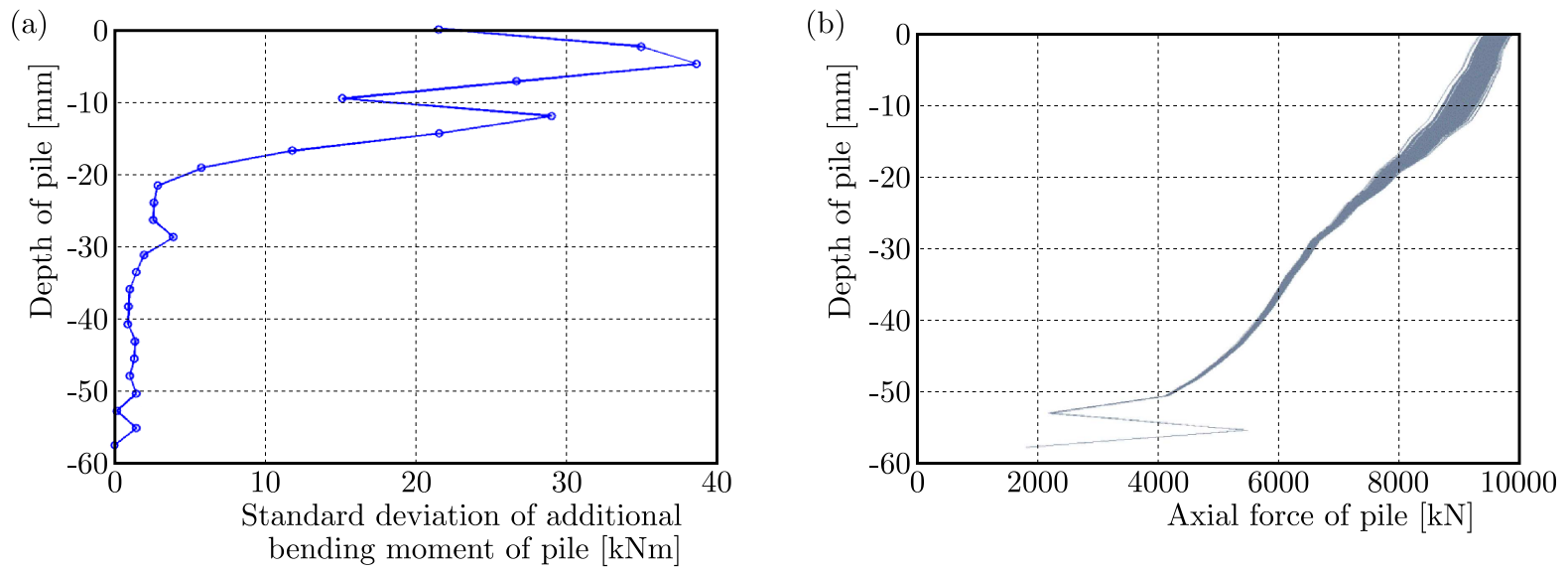

Fig. 9. (a) The standard deviation of the additional bending moment of the pile foundation.

(b) The total axial force of the pile foundation
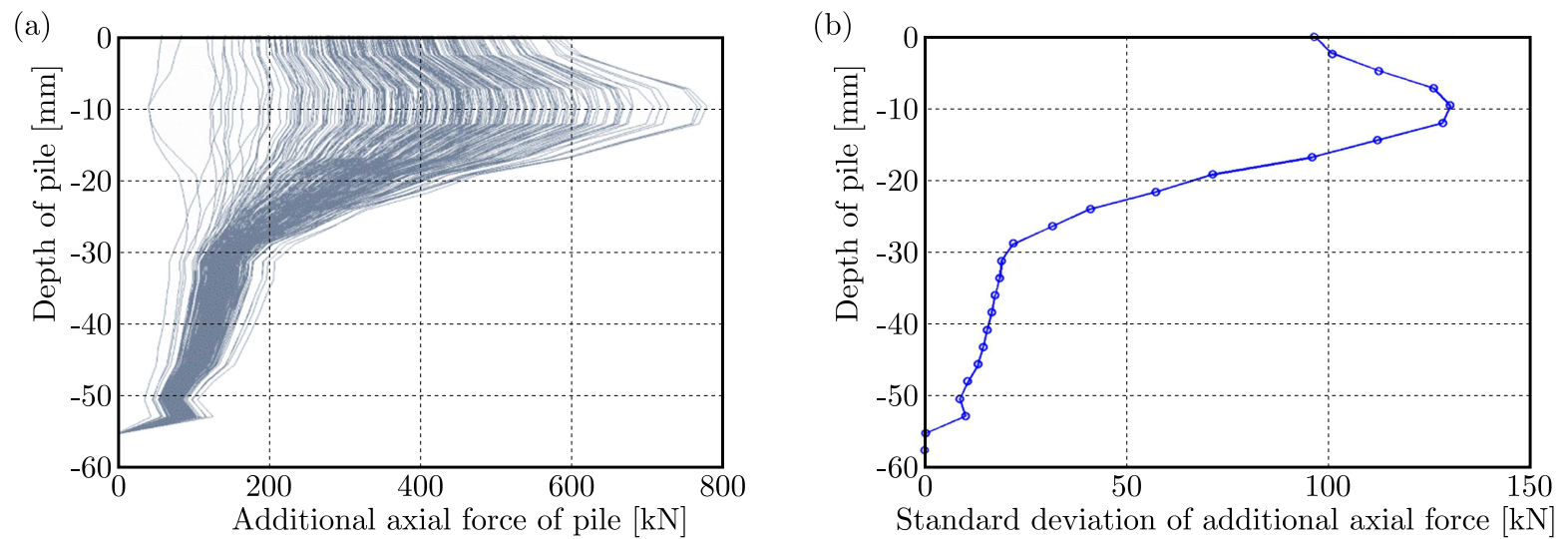

Fig. 10. (a) The additional axial force of the pile foundation and (b) standard deviation of the additional axial force of the pile foundation

fluctuation in the shield construction. The maximum additional axial force fluctuated within $100-800 \mathrm{kN}$, but its percentage was less than $10 \%$. Therefore, the shield tunnel construction process only slightly affected the axial force of the adjacent loaded-pile foundation. The standard deviation of the additional axial force of the pile foundation is shown in Fig. 10b. The maximum influence of the grouting pressure fluctuation on the pile additional axial force occurred at approximately $10 \mathrm{~m}$ below the surface (close to the tunnel buried depths). Moreover, the maximum value was approximately $135 \mathrm{kN}$.

The histogram of the frequency distribution of the pile additional axial force calculated for the grouting pressure of 300 groups at the center of the pile foundation $(30 \mathrm{~m})$ is shown in Fig. 11a. The additional axial force of the pile at this point roughly followed the skewed normal distribution. The histogram of the frequency distribution of the pile foundation additional bending moment calculated by 300 groups of the grouting pressure at $15 \mathrm{~m}$ is depicted in Fig. 11b. Similarly, the additional bending moment at this point roughly followed the skewed normal distribution. The additional axial force and the additional bending moment of the pile at other positions also generally followed the skewed normal distribution. A total of 10 sets of the calculated results were chosen randomly for chi-square tests ( $\chi 2$ tests) to verify whether they are conformed to the skewed normal distribution (Zhang et al. (2018)). The assumption that they all obeyed the skewed normal distribution was tested as follows. A total of 20 data intervals were divided into 18 groups, and the $\chi 2$ test was conducted. The results showed that the maximum difference degree was 12.783 , which was far less than the difference degree value 
of the $\chi 2$ test when the significance level was $5 \%$ (27.587). Thus, the assumption that the pile foundation additional bending moment and additional axial force obeyed the skewed normal distribution was verified.

(a)

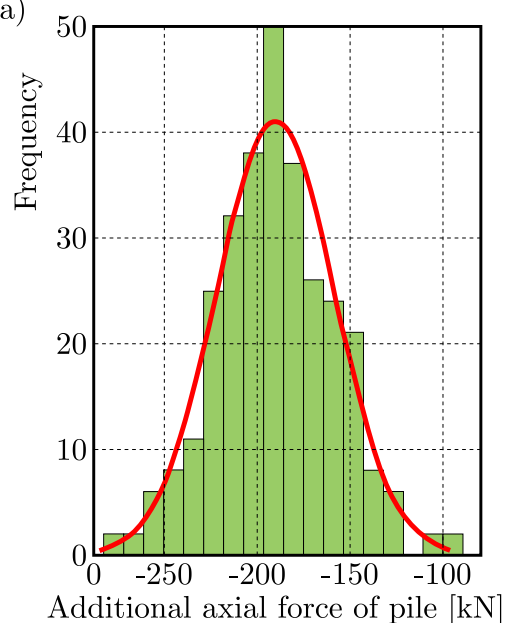

(b)

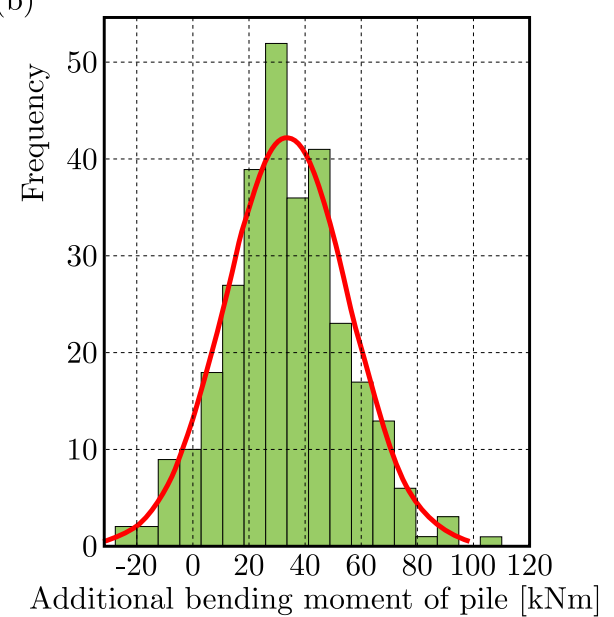

Fig. 11. Histogram of the frequency distribution of the pile foundation additional (a) axial force and (b) bending moments

\section{Additional response evaluation of adjacent loaded-pile foundations based on monitoring surface subsidence}

The numerical simulation considering the grouting pressure fluctuation can predict the influence range of the pile foundation. However, the calculation amount is too large, resulting in calculation costs. Adjacent loaded-pile foundations have been used in shield construction, making the monitoring instrument difficult to arrange on the piles. Ground subsidence along the line and around the pile foundation is usually monitored during subway construction. Thus, how to use the monitored surface settlement data should be determined to accurately reflect the influence of the construction process on the adjacent loaded-pile foundation.

\subsection{Establishment and validation of the mapping model}

The grouting pressure greatly affects the surface settlement along and around the subway, and this relationship is highly nonlinear. The flow chart and the purpose of establishing the mapping model are shown in Fig. 12. On the basis of the BP neural network algorithm, a mapping model between the previous 300 groups grouting pressures and the calculated ground surface settlements at different construction stages was established. Then, through the mapping model, the pressures near to actual grouting ones were restored by back analyzing the monitored surface subsidence. Finally, after verifying the model, the restored grouting pressures were used to analyze the influence on the adjacent loaded-pile foundations.

The positional relationship between the monitoring points and the numerical model is shown in Fig. 13a, and the observation points and the monitoring process are shown in Fig. 13b. The monitored data of different construction stages are summarized in Table 2.

The monitored data and the mapping model were used to obtain the grouting pressure values of each ring during construction. However, the data from each back analysis are not unique. Therefore, ten groups of grouting pressure parameters were obtained by conducting back analysis ten times. The results were input into the numerical model to calculate the surface subsidence at ten monitoring points. The simulated results and the monitored data were drawn in 


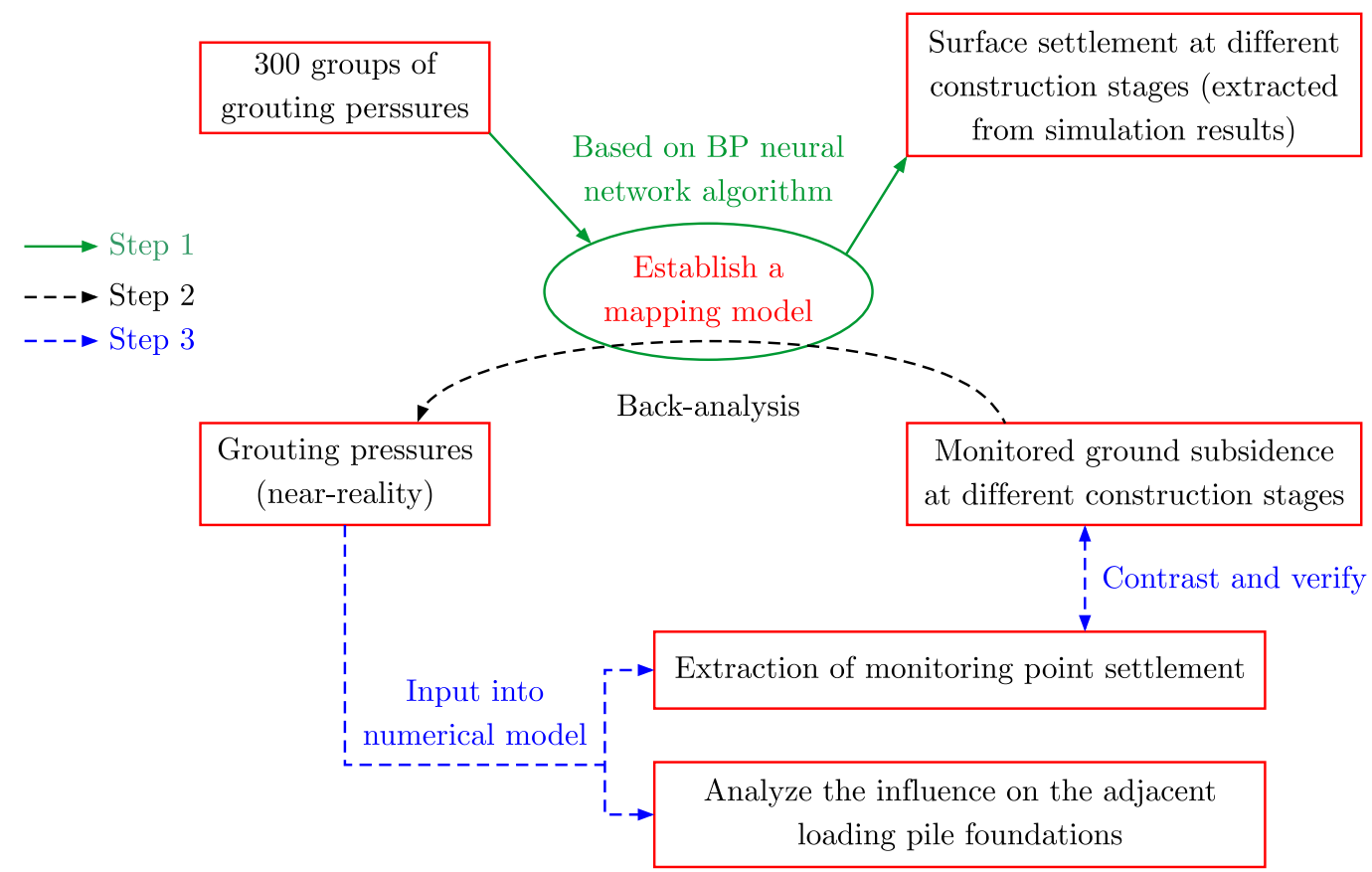

Fig. 12. Flow chart of the proposed mapping model development

(a)

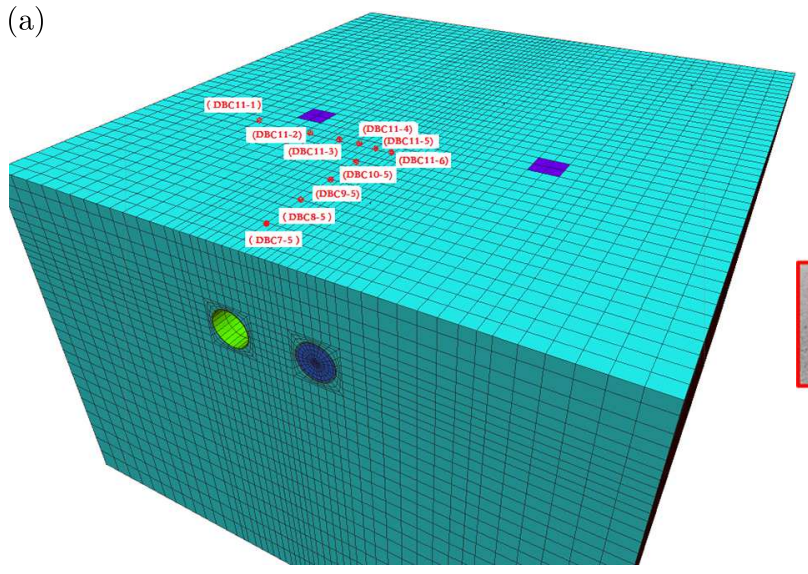

(b)

Fig. 13. Monitoring process and positional relationship of monitoring points: (a) positional relationship of monitoring points, (b) points and process of monitoring

Table 2. Monitored ground subsidence [mm]

\begin{tabular}{|c|c|c|c|c|c|c|c|c|c|c|}
\hline $\begin{array}{c}\text { Ring number } \\
\text { of shield } \\
\text { construction }\end{array}$ & \begin{tabular}{c} 
DBC \\
\cline { 2 - 12 }
\end{tabular} & $\begin{array}{c}\text { DBC } \\
8-5\end{array}$ & $\begin{array}{c}\text { DBC } \\
9\end{array}$ & $\begin{array}{c}\text { DBC } \\
10-5\end{array}$ & $\begin{array}{c}\text { DBC } \\
11-1\end{array}$ & $\begin{array}{c}\text { DBC } \\
11-2\end{array}$ & $\begin{array}{c}\text { DBC } \\
11-3\end{array}$ & $\begin{array}{c}\text { DBC } \\
11-4\end{array}$ & $\begin{array}{c}\text { DBC } \\
11-5\end{array}$ & $\begin{array}{c}\text { DBC } \\
11-6\end{array}$ \\
\hline \hline 20 & -3.13 & -0.54 & 1.85 & 0.83 & 0.77 & 1.03 & 1.19 & 1.17 & 0.99 & 1.44 \\
\hline 26 & -2.95 & -3.77 & 0.6 & -0.04 & -1.46 & -0.54 & -0.23 & -0.2 & -0.67 & -0.17 \\
\hline 32 & -7.56 & -4.38 & 0.47 & 0.42 & -0.22 & 0.06 & 0.38 & 0.2 & 0.48 & 0.13 \\
\hline 38 & -8.28 & -5.63 & -3.27 & -2.21 & -0.92 & -0.33 & 0.59 & -0.35 & 0.35 & 0.28 \\
\hline 44 & -8.23 & -6.13 & -4.81 & -4.61 & -0.45 & 0.45 & 0.3 & -1.21 & -0.71 & 0.22 \\
\hline 56 & -11.14 & -6.58 & -7.86 & -9.41 & -0.57 & -1.18 & -5.3 & -9.75 & -6.95 & -3.46 \\
\hline 66 & -11.37 & -8.36 & -8.47 & -10.89 & 1.00 & -0.79 & -7.97 & -13.98 & -10.81 & -6.76 \\
\hline 78 & -11.72 & -9.09 & -9.68 & -11.42 & 1.09 & -1.14 & -8.08 & -14.4 & -11.13 & -6.54 \\
\hline 84 & -12.33 & -9.81 & -10.22 & -10.82 & 0.4 & -0.52 & -7.86 & -13.89 & -9.88 & -5.16 \\
\hline
\end{tabular}


one coordinate system for different tunneling distances to verify the mapping and back analysis effects, as shown in Fig. 14. Ten sets of data were concentrated in an extremely narrow range, and the calculated results were in good agreement with the measured data in terms of trend and size. Thus, the mapping model and back analysis method were stable and effective.
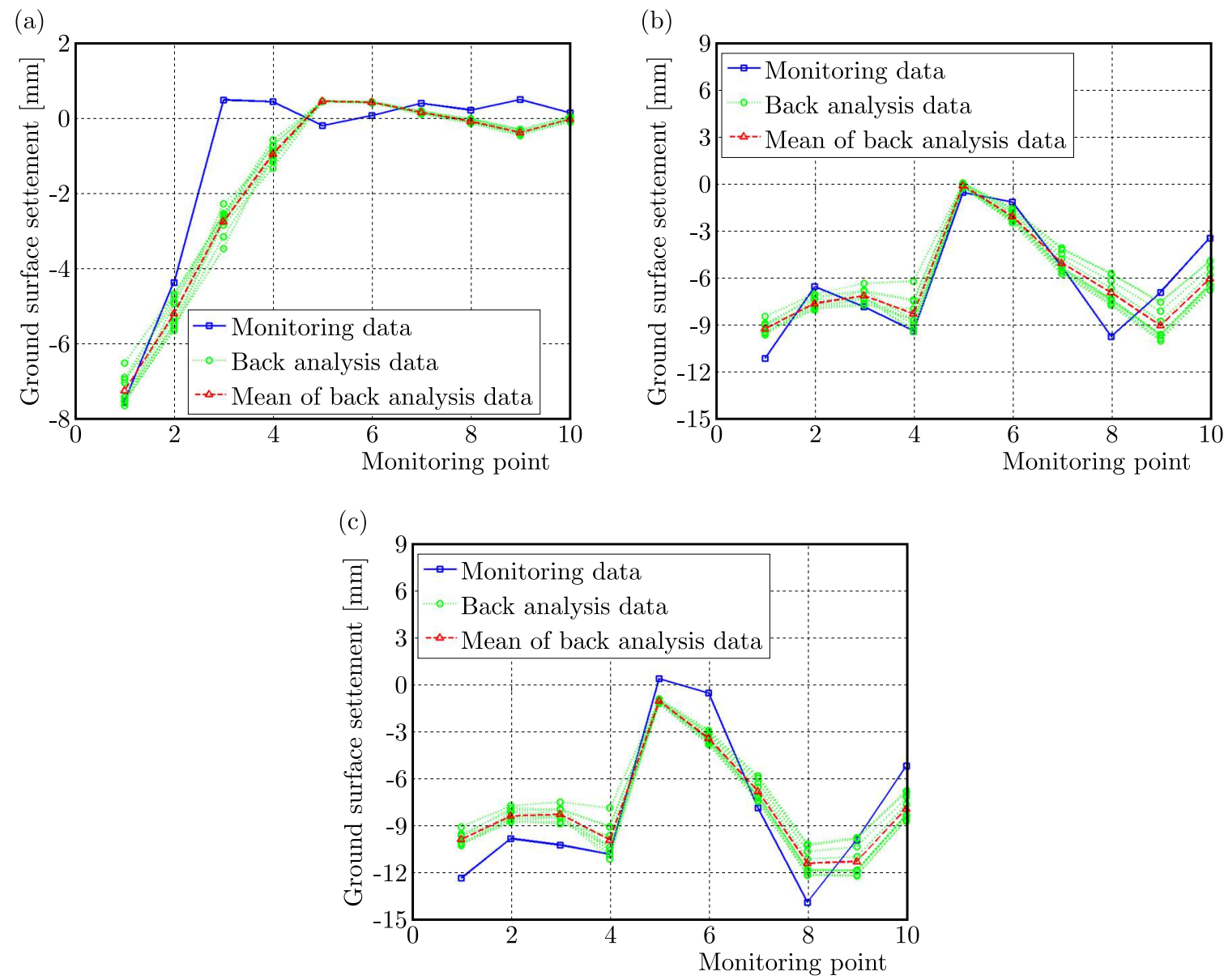

Fig. 14. Simulated results and monitored data for different tunneling distances: (a) tunneling to ring 32,

(b) tunneling to ring 56, (c) tunneling to ring 78

\subsection{Comparison and analysis of the influence of different methods on the additional response of pile foundation}

The superiority of the proposed method was tested as follows. The back analysis method calculation results of monitored data (average of ten calculations) were compared with the ordinary numerical method (without considering the grouting pressure fluctuation) for the influence of the additional pile foundation. The total pile lateral displacement for two numerical calculation methods is shown in Fig. 15a. The maximum value of pile lateral displacement calculated by the ordinary numerical simulation method is significantly smaller than that of the back analysis method.

The pile additional bending moment for two numerical calculation methods is depicted in Fig. 15b. The maximum additional bending moment obtained by the displacement back analysis is approximately 2.5 times greater than that of the ordinary numerical simulation method. If the ordinary numerical calculation results are continually used to evaluate the pile foundation additional response, the pile additional bending moment will be underestimated with great probability. This issue will cause great hidden danger to the engineering design and reinforcement. 
(a)

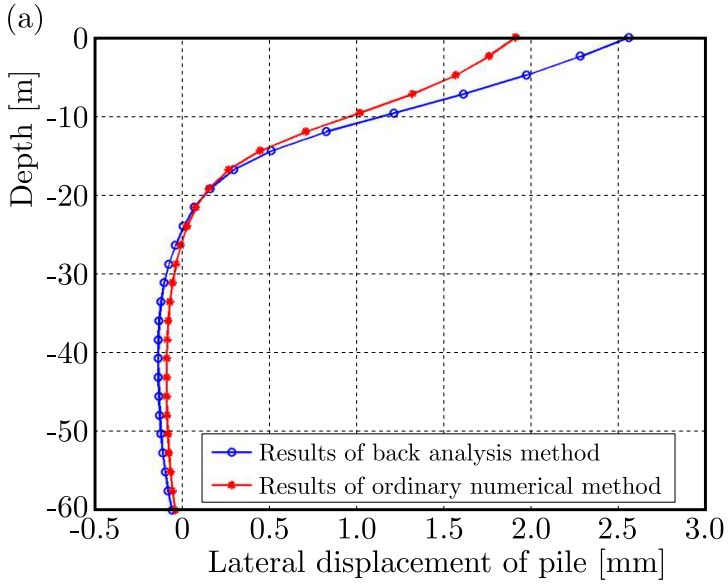

(b)

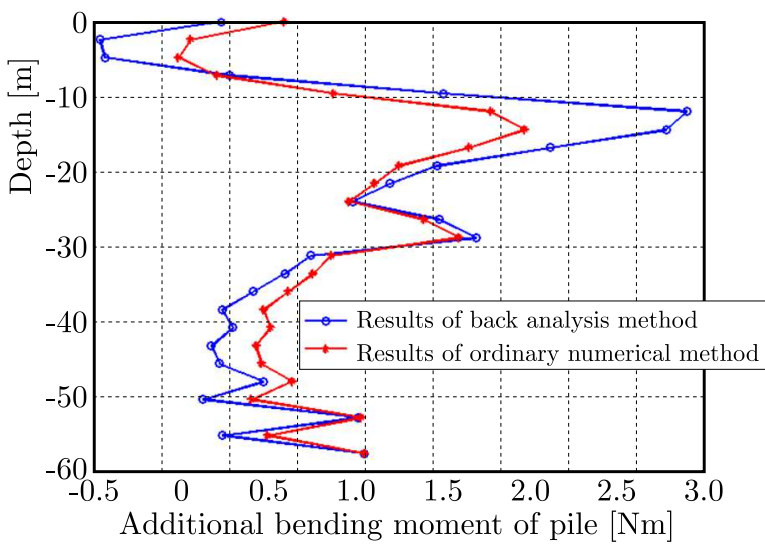

Fig. 15. (a) Total pile lateral displacement for two numerical calculation methods, (b) pile additional bending moment for two numerical methods

When the parameters used in the numerical method cannot reflect the actual project situation, the calculated results will also lose their significance for evaluation.

The pile additional axial force for two numerical methods is exhibited in Fig. 16. A great difference exists between the displacement back analysis and the ordinary numerical simulation results. The back analysis calculation results are larger than the results of the ordinary numerical method by about $60 \%-100 \%$. Using the back analysis calculation results to evaluate the pile foundation additional response can reduce the risk.

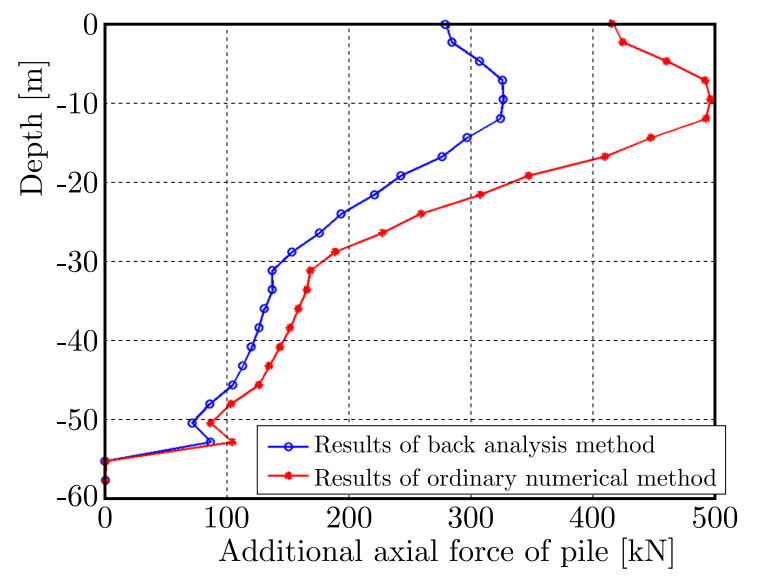

Fig. 16. Pile additional axial force for two numerical methods

\section{Conclusion}

In this study, the influence of the grouting pressure fluctuation on the adjacent loaded-pile foundation during shield tunnel construction was examined. The shield tunneling process under 300 groups of grouting pressure data was simulated using a refined numerical method. The influence rule of the grouting pressure fluctuation was also analyzed. The lateral displacement, additional axial force and bending moment of the pile foundation were considered in the analysis. The back analysis method was used based on the monitored settlement data to determine the effect of construction on the pile foundation. Finally, the results were compared with those of the common numerical simulation method. 
The following conclusions are derived from the simulation and comparison results:

- In shield tunneling, the pile foundation near the tunnel side and the starting station have the most obvious internal force changes. Thus, it is selected as a representative to analyze the effect on its additional response.

- The construction process considering the grouting pressure uncertainty greatly affects the adjacent pile additional response. The area with the great influence on the additional bending moment is ranging from 0-30 $\mathrm{m}$ below the ground (approximately 2.5 times deeper than the tunnel depth), and the area with the great influence on the additional axial force is near the tunnel depth.

- The chi-square $(\chi 2)$ test results show that when the grouting pressure of 300 groups obeys a skewed normal distribution, the pile foundation additional axial force and additional bending moment under the influence of the grouting pressure also follow the skewed normal distribution.

- The pile foundation additional response obtained by conducting the back analysis method based on the monitored displacement data is larger than that of the ordinary numerical simulation method. Thus, the back analysis calculation results are safer to evaluate the influence of shield tunneling on the response of the adjacent loaded-pile foundations.

Finally, it should be pointed out that all the above conclusions were only verified in 10 monitoring results of one model. To improve the accuracy and practicability of the model, more engineering verification is needed.

\section{Acknowledgments}

The authors thank the workers, foremen and safety coordinators of the main contractors for their participation. The authors also wish to thank engineers Xin He, Zheng Gao et al. for assistance in gathering field data. The authors also wish to thank Fang Xue and Yanli Dong (North University of China) for their assistance in the calculation process. This work was supported by National Key R\&D Program of China (Grant No.: 2018YFB1600100). This work was also supported by the Science and Technology Innovation Excellent Talents Project of Shanxi Province (No. 2016010514100002), Basic Apply Research Program of Shanxi Province (No.201901D211533), and Shanxi Transportation Holding Group Co., LTD Program (No. 19-JKKJ-69).

\section{References}

1. Aydan Ö., Hasanpour R., 2019, Estimation of ground pressures on a shielded TBM in tunneling through squeezing ground and its possibility of jamming, Bulletin of Engineering Geology and the Environment, 78, 5237-5251

2. BAKER J.W., FABER M.H., 2008, Liquefaction risk assessment using geostatistics to account for soil spatial variability, Journal of Geotechnical and Geoenvironmental Engineering, 134, 1, 14-23

3. Bezuijen A., van Der Schrier J., 2005, The influence of a bored tunnel on pile foundations, [In:] Tunnelling. A Decade of Progress, GeoDelft 1995-2005, A. Bezuijen, H. van Lottum (Edit.), 127

4. Chen T., Pang T., Zhao Y., Zhang D., Fang Q., 2018, Numerical simulation of slurry fracturing during shield tunnelling, Tunnelling and Underground Space Technology, 74, 153-166

5. Cui J., Xu W. H., Fang Y., Tao L. M., He C., 2020, Performance of slurry shield tunnelling in mixed strata based on field measurement and numerical simulation, Advances in Materials Science and Engineering, ID 6785260

6. Eshraghi A., Zare S., 2014, Face stability evaluation of a TBM-driven tunnel in heterogeneous soil using a probabilistic approach, International Journal of Geomechanics, 15, 6, 04014095 
7. Fenton G.A., Griffiths D.V., 2002, Probabilistic foundation settlement on spatially random soil, Journal of Geotechnical and Geoenvironmental Engineering, ASCE, 128, 5, 381-390

8. FLAC3D 3.0. 2009, Online Manual Table of Contents, Itasca International Inc.

9. Griffiths D.V., Fenton G.A., 2004, Probabilistic slope stability analysis by finite elements, Journal of Geotechnical and Geoenvironmental Engineering, ASCE, 130, 5, 507-518

10. Griffiths D.V., Huang J., Fenton G.A., 2009, Influence of spatial variability on slope reliability using 2-D random fields, Journal of Geotechnical and Geoenvironmental Engineering, ASCE, 135, 10, 1367-1378

11. LeE Y.J., BAssetT R.H., 2007, Influence zones for 2D pile-soil-tunnelling interaction based on model test and numerical analysis, Tunnelling and Underground Space Technology, 22, 3, 325-342

12. LeE Y.J., Yoo C.S., 2006, Behaviour of a bored tunnel adjacent to a line of loaded piles, Tunnelling and Underground Space Technology, 21, 3-4, 370

13. Li Z., Chen Z., Wang L., Zeng Z., Gu D., 2020, Numerical simulation and analysis of the pile underpinning technology used in shield tunnel crossings on bridge pile foundations, Underground Space, 6, 4, 396-408

14. Liu D., Wang F., Hu Q., Huang H., Zuo J., Tian C., Zhang D., 2020, Structural responses and treatments of shield tunnel due to leakage: A case study, Tunnelling and Underground Space Technology, 103, 103471

15. Loganathan N., Poulos H.G., Stewart D.P., 2000, Centrifuge model testing of tunnelling-induced ground and pile deformations, Geotechnique, 50, 3, 283-294

16. LV X.L., Zhao Y.C., CAI J.T., 2020, Numerical simulation of ground subsidence induced by shield tunnel construction disturbance in water-rich sandy stratum (in Chinese), Modern Tunnelling Technology, 57, 05, 104-109

17. WANG H.G., YU T.S., 2019, Influence of grouting pressure uncertainty on ground settlement induced by shield construction (in Chinese), Journal of Civil Engineering and Management, 36, 4, 102-107

18. Wang S.H., Zhao H.X., Jiang L., ET AL., 2014, Analysis of the impact on adiacent pile caused by excavation with metro shield based on two stage method (in Chinese), Journal of Northeastern University (Natural Science), 35, 6, 871-874

19. YANG H., Shi H., JiAnG X.L., LiU C., 2020, Influence of construction process of double-line shield tunnel crossing frame structure on ground settlement, Geotechnical and Geological Engineering, 38, $2,1531-1545$

20. Zhang C., Yang X., GaO H., 2018, Effect of randomness of interfacial properties on fracture behavior of concrete under uniaxial tension, Acta Mechanica Solida Sinica, 31, 2, 174-186

21. Zhang M., Li S., Li P., 2020, Numerical analysis of ground displacement and segmental stress and influence of yaw excavation loadings for a curved shield tunnel, Computers and Geotechnics, 118, 103325

22. ZHANG R.J., 2011, Analysis of excavation-induced additional responses of adjacent on-service pile foundations (in Chinese), Ph.D. Thesis, Huazhong University of Science and Technology, Wuhan

23. Zhang R., Hasan M.S.M.S., Zheng J., Cheng Y., 2018, Effect of spatial variability of engineering properties on stability of a CSMC embankment, Marine Georesources and Geotechnology, 36, 1, 91-99

24. Zheng G., Lu P., Cao J.R., 2015, Risk analysis based on the parameters sensitivity analysis for ground settlement induced by shield tunneling (in Chinese), Chinese Journal of Rock Mechanics and Engineering, 34, S1, 3604-3612 